\title{
Integrated approach to malaria prevention at household level in rural communities in Wakiso district, Uganda: impact evaluation of a pilot project
}

\author{
David Musoke ${ }^{1}$, George Karani ${ }^{2}$, Keith Morris ${ }^{2}$, Rawlance Ndejjo ${ }^{1}$, Edwinah Atusingwize ${ }^{1}$, \\ David Guwatudde ${ }^{3}$, Miph Boses Musoke ${ }^{4}$
}

1. Department of Disease Control and Environmental Health, School of Public Health, Makerere University College of Health Sciences, Kampala, Uganda.

2. Cardiff School of Health Sciences, Cardiff Metropolitan University, Wales, UK.

3. Department of Epidemiology and Biostatistics, School of Public Health, Makerere University College of Health Sciences, Kampala, Uganda.

4. School of Sciences, Nkumba University, Entebbe, Uganda.

\section{Email addresses}

GK: gkarani@cardiffmet.ac.uk, KM: kmorris@cardiffmet.ac.uk, RN: rndejjo@musph.ac.ug, EA: eatusingwize@musph.ac.ug, DG: dguwatudde@musph.ac.ug, MBM:musokemb@yahoo.com

\begin{abstract} on changes in knowledge and practices on malaria prevention. use in the community. use of multiple methods is promoted in communities.

DOI: https://dx.doi.org/10.4314/ahs.v18i4.35 dx.doi.org/10.4314/ahs.v18i4.35

\section{Corresponding author:}

David Musoke,

Department of Disease Control and Environmenta

Health, School of Public Health, Makerere University

College of Health Sciences, Kampala, Uganda.

(telephone: +256312263158; fax: +256414531807)

Email: dmusoke@musph.ac.ug
\end{abstract}

Background: The integrated approach to malaria prevention, which advocates for the use of several malaria prevention methods at households, is being explored to complement other existing strategies. We implemented a pilot project that promoted the integrated approach to malaria prevention in two rural communities in Wakiso district, Uganda.

Objectives: This paper presents the impact evaluation findings of the project carried out 2 years after implementation with a focus

Methods: The project evaluation was cross-sectional in design and employed both quantitative and qualitative data collection methods. The quantitative survey was conducted among 540 households (household heads being participants) while the qualitative component involved 4 focus group discussions among community health workers (CHWs). Chi-square test was used to compare quantitative results from the evaluation with those of the baseline while thematic analysis was employed for qualitative data.

Results: There was a statistically significant positive change in malaria prevention practices in the evaluation compared with the baseline regarding indoor residual spraying $\left(\chi^{2}=7.9, \mathrm{p}=0.019\right)$, mosquito screening of windows and ventilators $\left(\chi^{2}=62.3, \mathrm{p}=\right.$ $0.001)$, and closing windows of houses before $6: 00 \mathrm{pm}\left(\chi^{2}=60.2, \mathrm{p}<0.001\right)$. The CHWs trained during the project were found to be highly knowledgeable on the various malaria prevention methods in the integrated approach, and continued to promote their

Conclusion: Findings of the impact evaluation give promise that utilisation of integrated malaria prevention can be enhanced if

Keywords: Malaria, prevention, integrated malaria prevention, knowledge, practices, Uganda.

Cite as: Musoke D, Karani G, Morris K, Ndejjo R, Atusingwize E, Guwatudde D, Musoke MB. Integrated approach to malaria prevention at household level in rural communities in Wakiso district, Uganda: impact evaluation of a pilot project. Afri Health Sci. 2018;18(4): 1144-1156. bttps://

\section{Introduction}

Malaria continues to cause severe morbidity and mortality in sub-Saharan Africa. In 2015, Uganda ranked fourth among highest malaria burden countries in the WHO African region ${ }^{1}$. To reduce the burden of malaria, global and national mosquito vector control programmes are mainly using long lasting insecticidal nets (LLINs) and indoor residual spraying (IRS).However, with increased 
exposure to mosquito bites outside bedtime hours ${ }^{2}$ and resistance to insecticides ${ }^{3}$, there is need to explore other methods and practices that can reduce the occurrence of malaria. To complement existing malaria prevention interventions, other important measures can be used at households to significantly reduce mosquito vectors which transmit malaria. These include improving housing quality notably installing screening in ventilators and open eaves to prevent entry of mosquitoes; larval source management; and early closing of windows and doors on houses ${ }^{4,5,6}$. While these malaria prevention methods have been shown to individually contribute to reducing the occurrence of the disease, there is need for more evidence on their use in a holistic approach to complement existing strategies $^{3}$. The integrated approach to malaria prevention, which advocates use of several malaria prevention methods at households, is therefore being explored to reduce the burden of the disease. Such multi-interventional approaches have been used in control of other diseases such as HIV/AIDS and those affecting the cardiovascular system ${ }^{7,8}$.

We previously implemented a pilot project using the integrated approach to malaria prevention in two rural communities in Wakiso district, Uganda'. This project involved advocating and implementing several methods in a holistic manner geared towards reduction in mosquito populations in the communities and households. The specific malaria prevention methods promoted were use of insecticide treated nets (ITNs); IRS; insecticide sprays; removal of mosquito breeding sites; larviciding; installing mosquito screening in windows, ventilators and open eaves; and closing windows and doors early in the evenings. In the pilot project, we conducted a baseline survey on malaria prevention; trained community health workers (CHWs) and sensitised the community on integrated malaria prevention; and established 40 demonstration households implementing the integrated approach to malaria prevention within the community ${ }^{9}$.

The fundamental theory of change was to use the pilot project to improve knowledge and practices on malaria prevention in the community which would contribute to reduction in the occurrence of the disease and its associated consequences. The baseline survey conducted provided information on knowledge and practices on malaria prevention ${ }^{10}$ that informed and guided implementation of project activities. The training of CHWs and sensitisation of the community was aimed at improving knowledge, attitudes and practices on malaria prevention. The establishment of demonstration households was for the community to learn from them and appreciate use of the integrated approach hence lead to increased utilisation of the various malaria prevention methods.

An initial project (endline) evaluation undertaken highlighted benefits of the project to the community that included improvement in knowledge and practices on malaria prevention ${ }^{9}$. However, this evaluation was done immediately after its implementation hence the long-term impact of interventions could not be determined. Having only carried out an endline assessment necessitated an impact evaluation conducted 2 years after project implementation to establish any long-term benefits of the project. This paper presents findings from the impact evaluation of the project that promoted the integrated approach to malaria prevention in two rural communities in Wakiso district, Uganda.

\section{Methods}

\section{Study area}

The impact evaluation was carried out in Lukose and Mayanzi villages in Wakiso district located in the central region of Uganda. Wakiso district encircles Kampala, the capital city of the country and is rapidly becoming urbanised. The study villages are predominantly rural with inhabitants carrying out several activities including agriculture, animal farming and small-scale business. As Mayanzi village is located near the shores of Lake Victoria, some residents were specifically involved in fishing. Brick making is a common economic activity in Lukose village and a source of livelihood for part of the population.

\section{Study design and data collection}

The impact evaluation, conducted 2 years after implementation of the pilot project, was cross-sectional in design and employed quantitative and qualitative data collection methods. The quantitative survey was conducted among 540 households in the 2 villages in Wakiso district, Uganda where the pilot project was implemented. The questionnaire and observational checklist used during the baseline survey (carried out among 376 households) was 
employed for the impact evaluation to measure changes in knowledge and practices in malaria prevention following the project's interventions (including sensitisation and demonstration households). Whereas the questionnaire assessed knowledge and practices on malaria prevention, the checklist was used to establish environmental risk factors for malaria at households. The malaria prevention methods and risk factors assessed were use of mosquito nets (treated or untreated), IRS, time of closing of windows, screening of ventilators and windows, presence of stagnant water, use of insecticide sprays, and presence of overgrown vegetation near houses. Presence of stagnant water and overgrown vegetation assessed using the observational checklist were established within 5 metres from houses. Households involved in the quantitative survey were selected using systematic sampling, the sampling interval for each village obtained based on the estimated number of households therein. The reference household for systematic sampling was randomly selected in each village.

The sampling procedure used in the impact evaluation was as employed in the baseline survey'. The study population were members of the community while participants were household heads or any other responsible adults found at home during data collection. Only one participant from each selected household was involved in the study. The qualitative component of the study involved 4 focus group discussions (FGDs) among the CHWs who were trained on integrated malaria prevention in the pilot project. The 4 FGDs were sufficient to reach data saturation for the key issues being assessed in the impact evaluation. Two FGDs were conducted in each of the study villages and comprised of between 6 to 8 members. The FGDs were used to explore the CHWs' knowledge on the integrated approach to malaria prevention, their role in promoting use of multiple malaria prevention methods in the community, and community practices on preventing malaria. Photographs of the 40 demonstrations houses using integrated malaria prevention established during the pilot project 10 were taken with particular emphasis on screening installed in windows and ventilators.

\section{Data analysis}

Quantitative data was entered in SPSS version 17 (Chicago, Illinois, USA) and analysed in STATA version 12 (Col- lege Station, Texas, USA) statistical software. Frequencies and percentages from the impact evaluation were compared with those from the baseline survey to assess changes in knowledge and practices on malaria prevention in the community following implementation of the pilot project. Knowledge was assessed by awareness on individual malaria prevention methods and also multiple interventions using a scale. The knowledge assessment scale was derived from the question that established the malaria prevention methods participants were aware of. The probable responses to the knowledge question were use of untreated mosquito nets, ITNs, mosquito coils, insecticide sprays, skin mosquito repellents, taking preventive medicine, removing mosquito breeding sites, and any other method mentioned. Participants who were aware of either none or only 1 method were categorised as having no / low knowledge; those aware of 2 to 4 methods were categorised as having medium knowledge; while those aware of 5 or more methods where categorised as having high knowledge. The chi-square test was used to compare the quantitative results from the impact evaluation with those of the baseline survey to measure statistically significant change in the community. For the qualitative component, FGDs were tape recorded and transcribed verbatim in Luganda, the main local language used in central Uganda. The transcription was then validated by the principal investigator and another researcher. Thereafter, the typed narratives were translated into English and verified for accuracy by a researcher who was skilled in both languages. A list of codes was initially developed from the study objectives while others were identified after reviewing the transcribed data several times. The codes employed in the analysis were used to describe groups of words that had related or similar meaning. Atlas ti version 6.0.15 qualitative data analysis software was used to code and analyse the data. Using thematic analysis, emerging themes from the data were created, that were the basis of the qualitative results from the evaluation.

\section{Ethical considerations}

The study was approved by the institutional review boards of Cardiff School of Health Sciences, UK and Makerere University School of Public Health, Uganda. The study was also registered at the Uganda National Council for Science and Technology. Village leaders were informed 
about the study and written informed consent obtained from participants (including heads of the demonstration households) before taking part. All participation in the study was voluntary.

\section{Results}

\section{Demographics of participants}

Many categories of demographic information of partici- pants of the impact evaluation were generally comparable to those of the baseline survey [such as participants aged 25 - 34 years (33.8\% versus $35.4 \%$ ); and households earning between 20 and 60 US dollars per month (49.2\% versus $48.7 \%$ ) for the baseline survey and impact evaluation respectively]. However, there were differences between the baseline survey and impact evaluation in a number of variables including occupation $\left(\chi^{2}=30.09, \mathrm{p}<0.001\right)$ and household size $\left(\chi^{2}=34.10 \mathrm{p}<0.001\right)$ (Table 1$)$.

Table 1 Comparison of socio-demographic characteristics of participants between baseline survey and impact evaluation

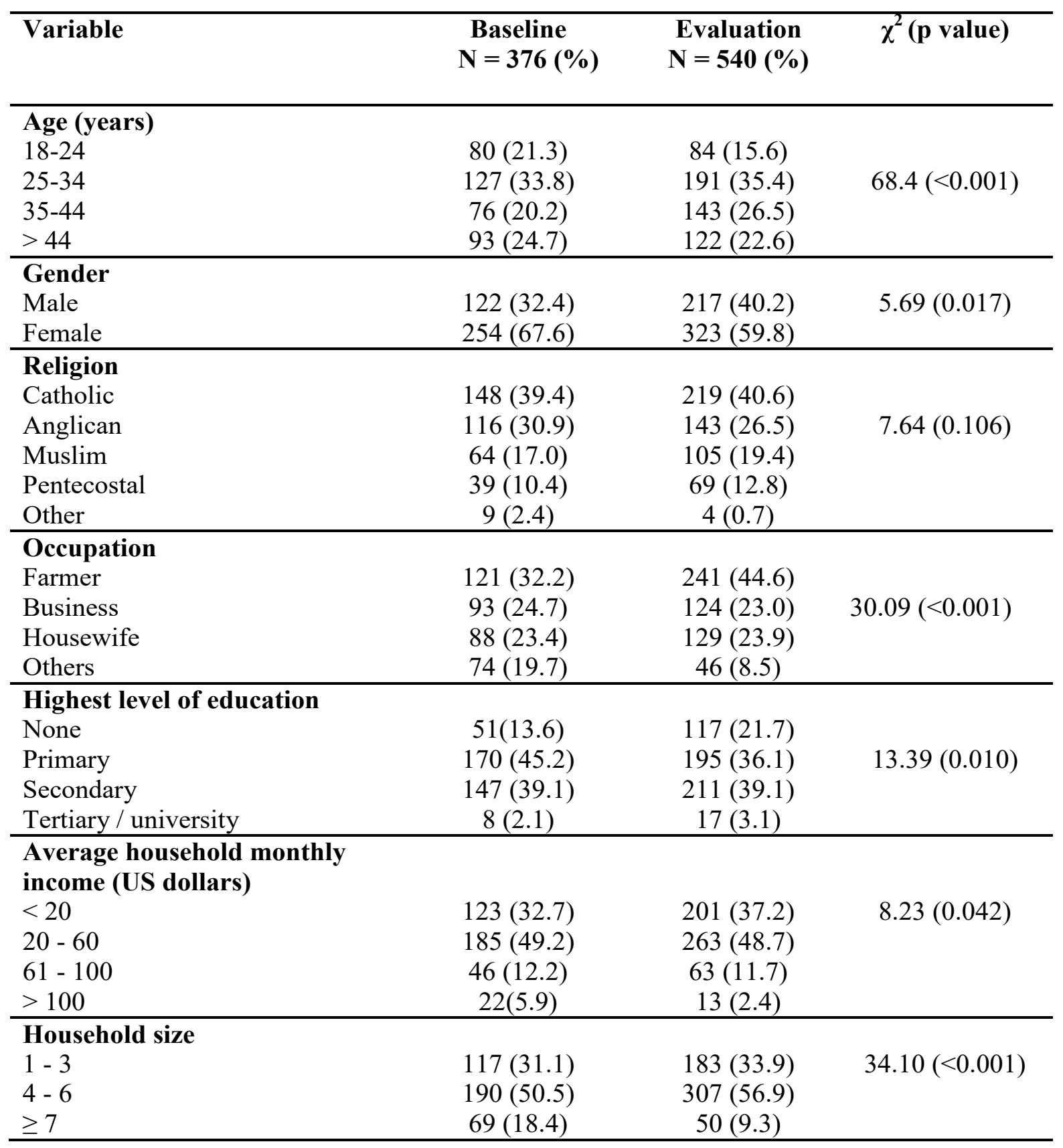


Knowledge on malaria transmission and prevention Although majority of participants in the baseline survey $(89.9 \%, \mathrm{n}=337)$ were aware that malaria was transmitted through mosquito bites, awareness was higher in the impact evaluation $(97.2 \%, \mathrm{n}=525)$. More participants in the impact evaluation $(91.7 \%, \mathrm{n}=495)$ were aware of ways to avoid getting malaria compared to the baseline survey $(68.4 \%, \mathrm{n}=257)$. Knowledge on one or more malaria prevention methods was higher in the impact evaluation $(90.6 \%, \mathrm{n}=489)$ in comparison to the baseline survey $(67.6 \%, \mathrm{n}=254)$. From the knowledge assessment scale, more participants in the impact evaluation $(66.5 \%$, $\mathrm{n}=359)$ had medium knowledge on malaria prevention methods compared to the baseline survey $(51.9 \%, \mathrm{n}=$ 195). However, a few participants had high knowledge on malaria prevention methods in both the baseline survey $(0.8 \%, \mathrm{n}=3)$ and impact evaluation $(3.0 \%, \mathrm{n}=16)$ while those with low / no knowledge were higher in the baseline survey $(47.3 \%, \mathrm{n}=178)$.

Knowledge on sleeping under untreated mosquito nets to prevent malaria was lower in the impact evaluation $(67 \%, \mathrm{n}=362)$ compared to baseline survey $(82 \%, \mathrm{n}=$ 308). However, there was a slight increase in knowledge of ITNs in the impact evaluation $(32 \%, \mathrm{n}=173)$ in comparison with the baseline survey $(30 \%, \mathrm{n}=113)$. Knowledge on use of mosquito skin repellents $(23 \%, \mathrm{n}=124$ versus $14 \%, \mathrm{n}=53$ ), and removal of mosquito breeding sites $(51 \%, \mathrm{n}=275$ versus $7 \%, \mathrm{n}=26)$ was higher in the impact evaluation in comparison with the baseline survey respectively (Figure 1). However, from the knowledge assessment scale which assessed knowledge on multiple malaria prevention methods, no statistically significant difference in knowledge was observed in the impact evaluation group compared with the baseline survey $\left(\chi^{2}=\right.$ 1.87; $\mathrm{p}=0.392)$.

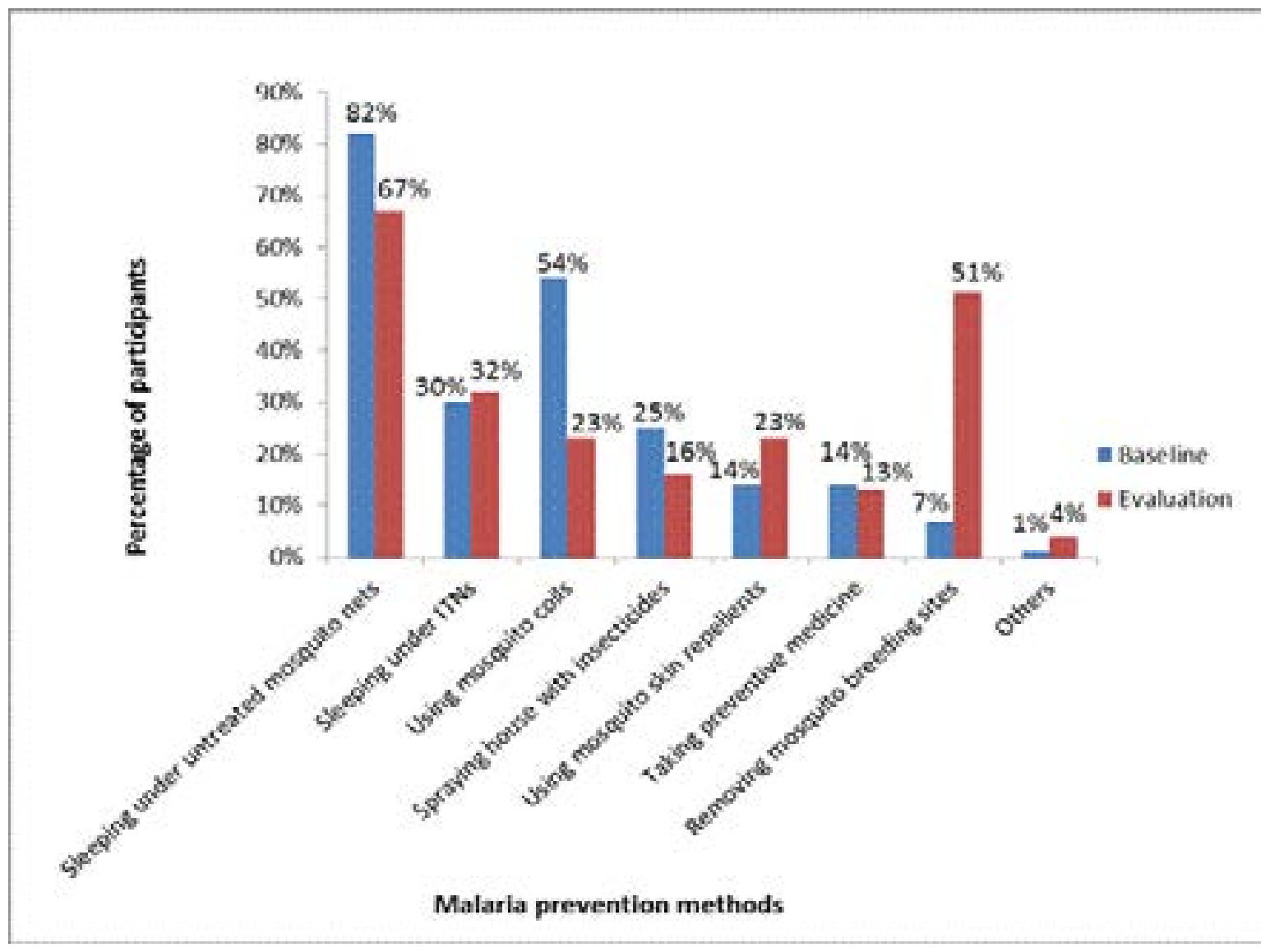

Figure 1 Comparison of knowledge on individual malaria prevention methods between the baseline survey and impact evaluation 
From the FGDs, CHWs were highly knowledgeable about the various malaria prevention methods advocated in the integrated approach. These included sleeping under ITNs, screening of houses, removing mosquito breeding sites, and early closing of doors on houses. However, they noted that although they continued to promote these malaria prevention methods in their communities, some section of the population were not keen to learn about them. It was also established that to further increase community knowledge on malaria prevention, continuous sensitisation by personnel who were not members of the villages was needed. This was because the CHWs were at times despised by some members of the community due to being accustomed to them and also their generally low education status. Below are quotations demonstrating high knowledge of CHWs and related issues regarding integrated malaria prevention in the community.

"Regarding how to avoid getting malaria, there is slashing overgrown grass from our surroundings. We also need to close doors and windows early in the evening throughout the night, sleeping under insecticide treated mosquito nets, and draining all mosquito breeding places near our homes. There is also indoor residual spraying and larviciding to kill mosquito larvae. Removal of bottles and other containers from our compounds is also important." CHWs FGD, Lukose

"Some of these community members know about those malaria prevention methods though there are still those who do not take them seriously. There are also people who are layy to take up those methods and they do not look at them as being important. There are those you will find in rental houses with bushes around their premises and they claim that they are waiting for the landlord to do the slashing and not knowing that they too can do something." CHWs FGD, Mayanzi

\section{Practices on malaria prevention}

The positive changes in practices on malaria prevention between the impact evaluation and baseline survey that were statistically significant were use of IRS in the previous twelve months $\left(\chi^{2}=7.9 ; \mathrm{p}=0.019\right)$, presence of mosquito screening in windows and ventilators $\left(\chi^{2}=\right.$ 62.3; $\mathrm{p}<0.001)$, and closing windows before $6.00 \mathrm{pm}\left(\chi^{2}\right.$ $=60.2 ; \mathrm{p}=0.001)$. However, there was a statistically significant negative change between the impact evaluation and baseline survey regarding presence of stagnant water in compounds $\left(\chi^{2}=12 ; \mathrm{p}=0.001\right)$ (Table 2$)$. 

Table 2: Comparison of malaria prevention practices at households between the baseline
and evaluation

\begin{tabular}{|c|c|c|c|c|c|}
\hline Variable & Category & $\begin{array}{l}\text { Baseline } \\
\mathrm{N}=376(\%)\end{array}$ & $\begin{array}{l}\text { Evaluation } \\
\mathrm{N}=\mathbf{5 4 0}(\%)\end{array}$ & $\begin{array}{l}\text { Chi } \\
\text { square } \\
\chi 2\end{array}$ & $P$ value \\
\hline $\begin{array}{l}\text { Presence of at least } \\
\text { one mosquito net in } \\
\text { household }\end{array}$ & Yes & $205(54.5)$ & $\begin{array}{l}247(45.7) \\
293(54.3)\end{array}$ & 0.0061 & 0.938 \\
\hline $\begin{array}{l}\text { Used indoor residual } \\
\text { spraying in previous } \\
12 \text { months }\end{array}$ & Yes & $\begin{array}{r}2(0.5) \\
374(99.5)\end{array}$ & $\begin{array}{r}17(3.2) \\
523(96.9)\end{array}$ & 7.9 & $0.019^{*}$ \\
\hline $\begin{array}{l}\text { Presence of mosquito } \\
\text { screening in windows } \\
\text { and ventilators }\end{array}$ & $\begin{array}{l}\text { Yes } \\
\text { No }\end{array}$ & $\begin{array}{r}8(2.1) \\
368(97.9)\end{array}$ & $\begin{array}{l}106(19.6) \\
434(80.4)\end{array}$ & 62.3 & $<0.001 *$ \\
\hline $\begin{array}{l}\text { Presence of stagnant } \\
\text { water in compound }\end{array}$ & $\begin{array}{l}\text { Yes } \\
\text { No }\end{array}$ & $\begin{array}{r}66(17.6) \\
310(82.5)\end{array}$ & $\begin{array}{l}148(27.4) \\
392(72.6)\end{array}$ & 12.0 & $0.001 *$ \\
\hline $\begin{array}{l}\text { Presence of vessels } \\
\text { around house that can } \\
\text { potentially hold water } \\
\text { for mosquito } \\
\text { breeding }\end{array}$ & Yes & $236(62.8)$ & $\begin{array}{l}195(36.1) \\
345(63.9)\end{array}$ & 0.1 & 0.729 \\
\hline $\begin{array}{l}\text { Closed windows on } \\
\text { houses before } 6.00 \mathrm{pm}\end{array}$ & $\begin{array}{l}\text { Yes } \\
\text { No }\end{array}$ & $146(45.1)$ & $\begin{array}{l}364(71.9) \\
142(28.1)\end{array}$ & 60.2 & $<0.001 *$ \\
\hline $\begin{array}{l}\text { Presence of } \\
\text { overgrown vegetation } \\
\text { within } 5 \text { metres of } \\
\text { house }\end{array}$ & Yes & $215(57.2)$ & $290(53.7)$ & 1.1 & 0.298 \\
\hline
\end{tabular}

* Statistically significant at $\mathrm{p}<0.05$

CHWs reported that they promoted use of several malaria prevention methods in the community during their routine work including management of childhood illnesses. Some of the methods had been embraced by the community such as removing mosquito breeding sites. However, several challenges were identified for the nonuse of other methods. Indeed, although methods such as screening of houses to prevent mosquito entry were appreciated by many households, they lacked resources required to have such screens installed. From the FGDs, it was established that the screens installed in the windows and ventilators of the demonstration houses of the pilot project (Figures 2, 3 and 4) continued to be seen by community members in addition to the CHWs sensitisation. Sleeping under mosquito nets was also found to partly lead to complacency regarding use of other malaria prevention methods. Some of the challenges are demonstrated in the quotations below. 


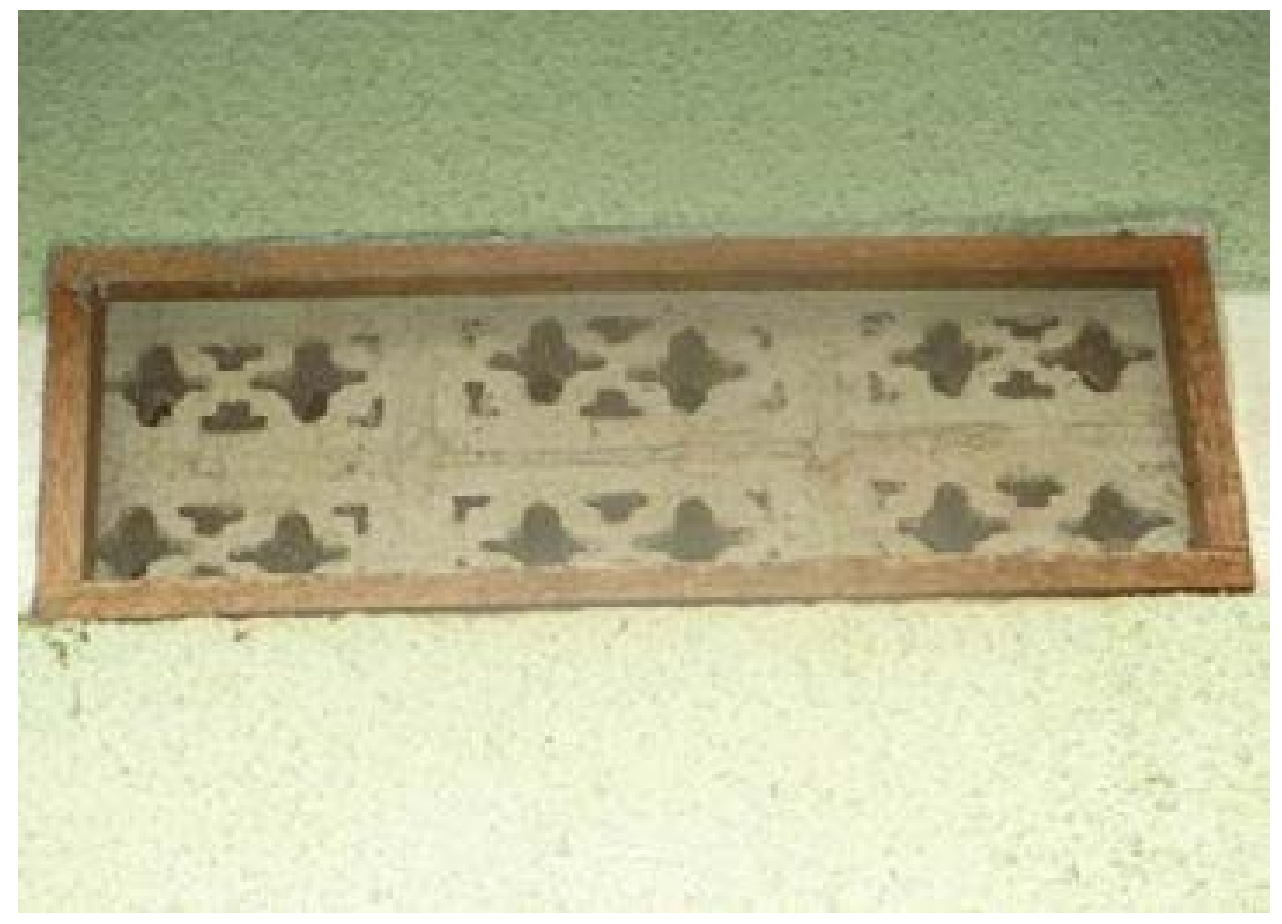

Figure 2. A ventilator with screening on one of the demonstration houses.

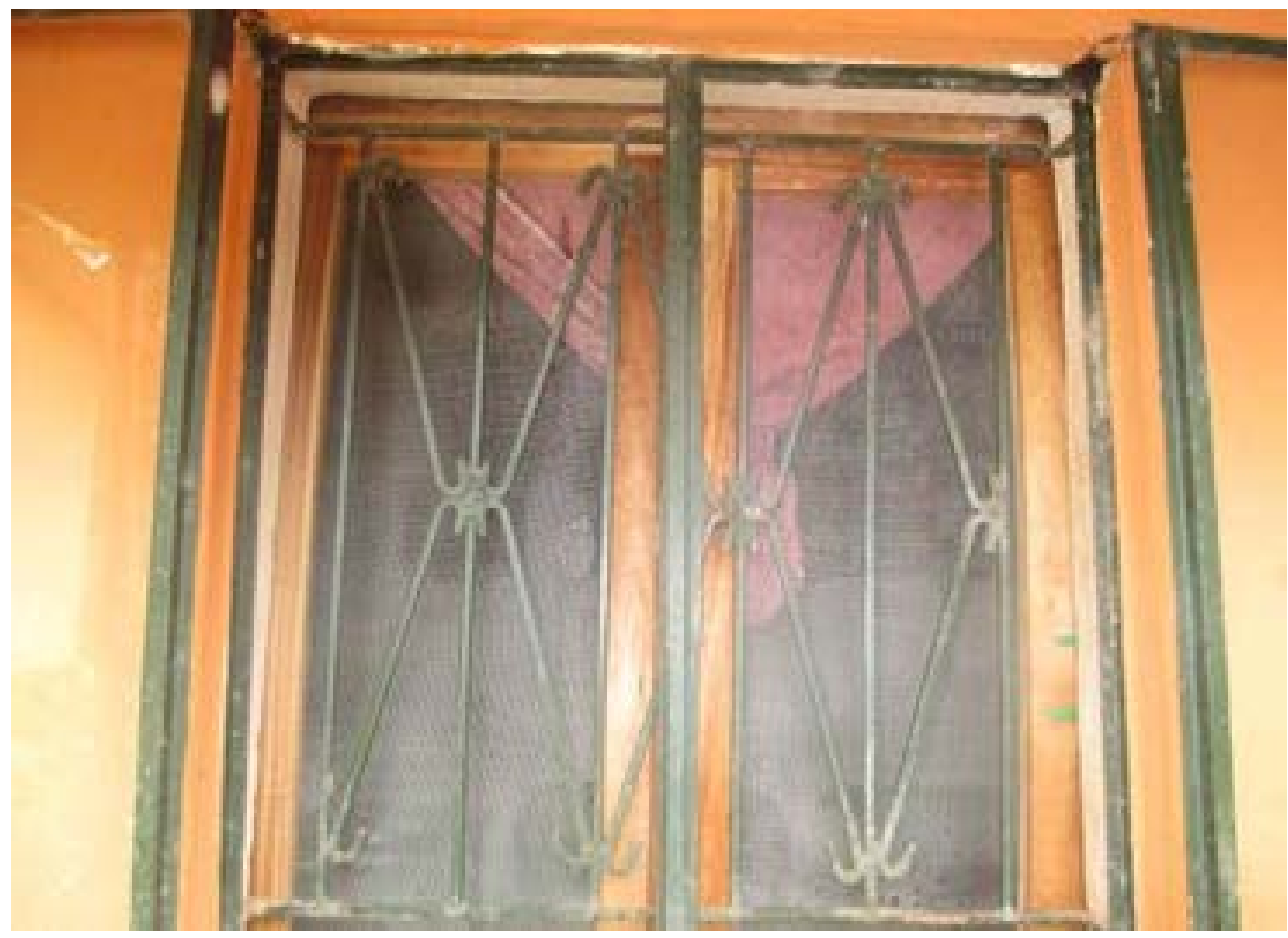

Figure 3. A window with screening on one of the demonstration houses. 


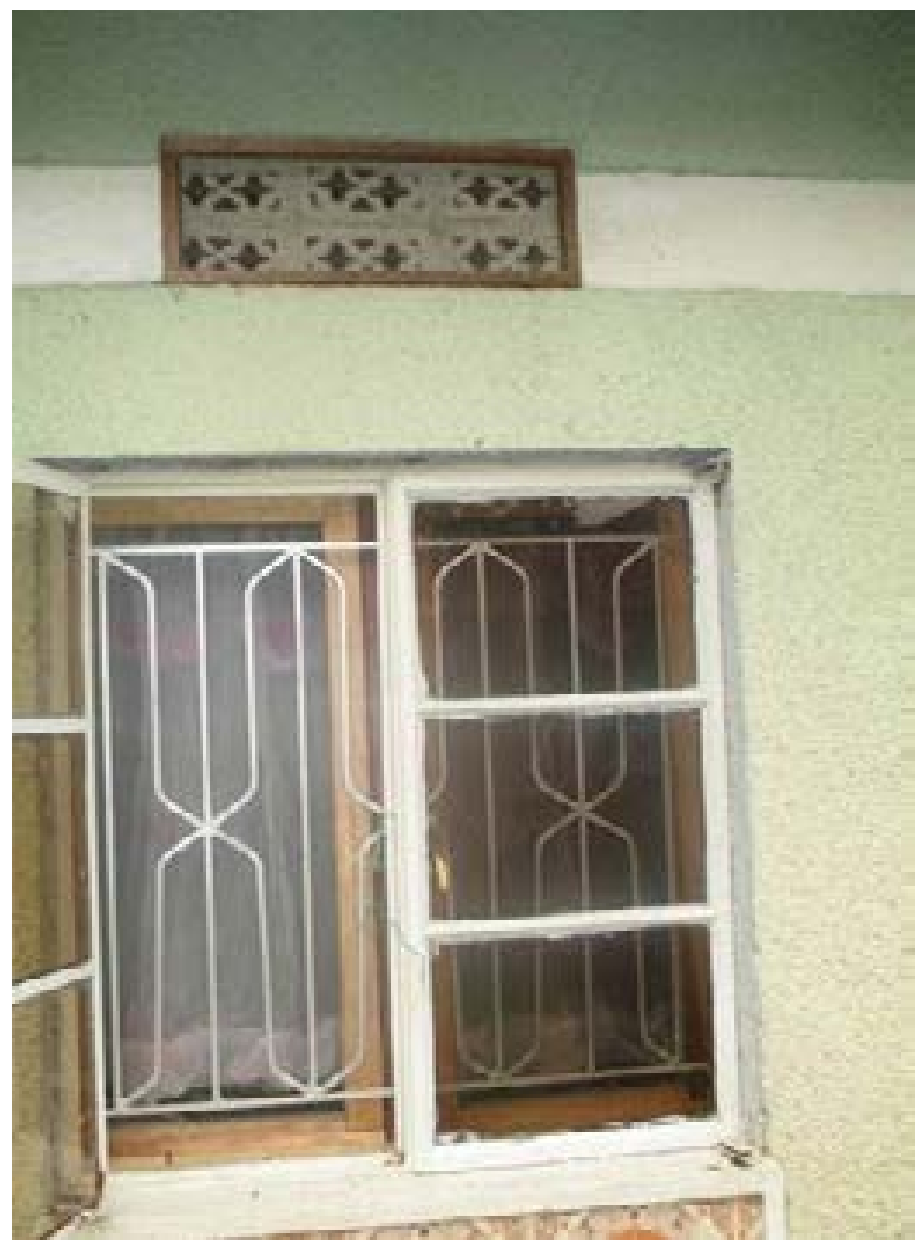

Figure 4. A ventilator and window with screening on one of the demonstration houses.

"Whenever we are treating children in our community, we tell people about various prevention methods that they can embrace in their households to prevent malaria. We tell them that they need to remove all bottles from the compound and slash all overgrown vegetation in the compound. We also encourage them to close the doors and windows early in the evening at around 5.00 pm before the mosquitoes enter the houses because even if you sleep under a mosquito net, the mosquitoes can still bite you when you are in the sitting room watching television. We also tell them to drain all breeding places of mosquitoes and for the permanent ponds, we encourage them to pour oil on top of the stagnant water to kill mosquito larvae. We also advocate use of insecticides like Doom ${ }^{\mathrm{TM}}$ to kill mosquitoes." CHWs FGD, Mayanzi

"Community members now mind about water ponds in the area. There is a place I passed and found a lady and her daughter trying to drain stagnant water from the road and she told me it would breed mosquitoes if left unattended to. Such practices are done by people who bave been taught about malaria prevention. The others would ask why they have to waste their time doing such a thing and what they would benefit from it not knowing that since they are close to these pools of water, the mosquitoes could harm them." CHWs FGD, Lukose

"There are some households that close their windows very late in the night at around $10.00 \mathrm{pm}$ saying that their houses are very hot and either lack ceilings or the ceilings are within a short distance from the ground therefore they need to open the doors and windows for a long time to get rid of the accumulated heat. Others claim that they don't mind about mosquitoes entering their houses as they sleep under mosquito nets not knowing that the mosquitoes could still bite them during the time they are not in bed." CHW FGD, Mayanzi Although sleeping under treated mosquito nets was predominantly used to prevent malaria, it was noted from the FGDs that the community was mainly using those provided by the government free of charge with only a 
few households buying new nets. Even households that could afford to buy nets often waited to receive those for free. However, the nets provided by the government had become old and needed replacement. There was also low use of certain methods in the community such as IRS, mosquito coils, insecticide sprays and larviciding due to concerns about the potential effects on health as shown in the quotations below.

"Among the many malaria prevention methods, most community members use mosquito nets though the challenge with the nets is that they become old and get torn very fast yet the government takes a long time to distribute new ones. Another issue is that most people really yearn for the nets but do not have the money to buy them. I am one of the few people who bought myself a net but they are expensive and it is therefore a big sacrifice. Some women even pretend to be pregnant and go to the health centre to receive a free mosquito net." CHWs FGD, Lukose

"The use of indoor residual spraying is not liked by most community members as they say that the chemical used is harmful to bealth. They sometimes ask that why a chemical that remains on the walls and continues killing mosquitoes for a long time should be trusted. Our communities still need lot of sensitisation to change these negative attitudes towards some malaria prevention methods." CHWs FGD, Lukose

"The use of insecticide sprays is low in this village because they are bought in a small can which costs money so many community members have not embraced this method. We usually teach the community to spray the insecticide and leave the house for a minimum of 30 minutes before they can go back inside. The challenge is that many community members do not use it and many more do not even know how to use it. Other people say it negatively affects them when used and that it has adverse bealth effects including causing cancer." CHWs FGD, Mayanzi village

\section{Discussion}

This study demonstrates improvement in knowledge in some individual methods as well as practices on malaria prevention following interventions of the pilot project. However, there was no statistically significant improvement in knowledge of multiple malaria prevention methods. CHWs trained during the pilot project were knowledgeable on the various methods in integrated malaria prevention, and were involved in promoting improved practices in the communities. The findings of the impact evaluation suggest a general improvement in promotion and utilisation of integrated malaria prevention in the community following implementation of the pilot project. The differences observed in some demographic characteristics of participants of the impact evaluation in comparison to the baseline survey could be due to the relatively long time (over 2 years) between the two surveys.

From findings of the quantitative component of the impact evaluation, there was increase in knowledge on individual malaria prevention methods in the integrated approach such as use of mosquito skin repellents, and removal of mosquito breeding sites in comparison with the baseline. The community sensitisation carried out during the intervention is likely to have contributed to increase in knowledge in the community. Indeed, studies have shown that interventions aimed at creating awareness on public health issues contribute to increase in knowledge among populations ${ }^{11,12,13}$. However, from the knowledge assessment scale, changes in knowledge on multiple malaria prevention methods in the integrated approach in the impact evaluation in comparison with the baseline survey was not statistically significant. This could be an indication that the interventions of the project led to increase in knowledge on individual methods but with little influence on multiple methods. The lack of increase in knowledge on multiple methods may be attributed to the short duration of intervention phase of the pilot project (1 year). Moreover, malaria campaigns within the country only focus on a few prevention methods that could have ended up being entrenched in people's minds. Future programmes aimed at promoting the integrated approach to malaria prevention therefore need to intensify efforts of sensitisation and for longer durations so as to significantly influence changes in knowledge on multiple methods for greater public health impact.

CHWs trained during the project were found to be highly knowledgeable on the various malaria prevention methods in the integrated approach. These volunteers continued to promote the use of multiple malaria prevention methods in their villages, and are key in improving knowledge and practices on malaria control as has been established elsewhere ${ }^{14}$. However, several hindrances such as laziness and complacency of community members were 
identified as factors limiting communities from embracing many of the methods as has been found in other studies in sub-Saharan Africa ${ }^{15,16}$. It has also been shown in some malaria endemic communities that at times people do nothing to prevent the disease even when knowledgeable on methods that can be used ${ }^{17,18}$. This complacency in malaria prevention could be due to individuals being accustomed to the disease hence seeing no need for appropriate practices. It is therefore critical that such attitudes are changed by stakeholders concerned with malaria control in endemic countries such as health practitioners so as to reduce morbidity and mortality associated with the disease.

It was established that there was a significant positive change in malaria prevention practices in the impact evaluation compared with the baseline survey regarding use of IRS $\left(\chi^{2}=7.9, p=0.019\right)$, mosquito screening of windows and ventilators $\left(\chi^{2}=62.3, \mathrm{p}<0.001\right)$, and closing windows of houses before 6:00 pm $(\chi 2=60.2, \mathrm{p}<0.001)$ which were promoted in the pilot project. The interventions implemented in the project should therefore have contributed to the improvement in practices on malaria prevention in the community. Among the improved practices were house screening, and early closing of windows which are not among core current global and national malaria prevention efforts ${ }^{1}$. This implies that practices on malaria prevention beyond ITNs and IRS could improve if promoted extensively in communities. Indeed, although malaria prevention practices beyond ITNs and IRS are low in many malaria endemic communities ${ }^{17,18,19}$, community based programmes targeting several malaria prevention methods have reported improvements ${ }^{20}$ as was the case in this study. Therefore, utilisation of various malaria prevention methods could increase if campaigns targeting them are implemented as part of malaria control programmes. The statistically significant negative change regarding presence of stagnant water in compounds is likely due to the fact that data was collected at different times of the year for the baseline survey and impact evaluation. Indeed, it is known that mosquito breeding sites are more numerous in the rainy season (as was the case during the impact evaluation) in comparison with when it is $\mathrm{dry}^{21}$. Nevertheless, it is important to remove all present pools of stagnant water in communities irrespective of the season due to the occasional rains even during dry periods so as to reduce potential mosquito breeding sites. The main challenges identified during the impact evaluation from the FGDs among CHWs regarding utilisation of multiple malaria prevention methods were cost and negative attitude towards some of them. These challenges in malaria prevention practices were also identified in the baseline survey of the project ${ }^{10}$. This implies that even with interventions to promote integrated malaria prevention such as sensitisation (as was the case in the project), issues such as poverty in rural communities, which affect expenditure on malaria prevention, have an impact on practices. Indeed, poverty has been found to be a hindrance in use of various malaria prevention methods including ITNs and IRS ${ }^{22,23,24}$. Side effects such as skin irritation and smell resulting from use of insecticide-based methods has also been found elsewhere ${ }^{25}$. More sensitization of communities is therefore required so as to reduce the negative perceptions about methods that use insecticides as well as increase knowledge on their correct use to minimise side effects.

A limitation of the study is that being a non-experimental impact evaluation without a comparison group, changes in knowledge and practices on malaria prevention in the study community could have been contributed to by other sources beyond interventions of the pilot project. These other sources of information on malaria prevention could have come from government programmes during national campaigns such as distribution on LLINs including through mass media. Therefore, the improvement in knowledge and practices on malaria prevention in this research cannot be solely attributed to the interventions implemented during the project. Nevertheless, as the demonstration households using the integrated approach to malaria prevention that were established during the project reported benefits such as reduction in number of mosquitoes in their houses and less occurrence of malaria as presented in our earlier paper ${ }^{26}$, the interventions should have had a considerable positive impact in the community. Improvement in knowledge and practices on malaria prevention attributable to the interventions was also established during the endline evaluation conducted at the end of the project ${ }^{9}$. In addition, from the FGDs conducted among CHWs trained on the integrated approach, it was demonstrated that the community knowledge and practices were enhanced by the interventions 
implemented during the project. It should be noted that although knowledge and practices were assessed in the evaluation, changes in morbidity and mortality could have been established as a measure of impact of the project. However, assessment of malaria morbidity and mortality was beyond the scope of the impact evaluation.

\section{Conclusion}

There was improvement in knowledge as well as practices on malaria prevention following interventions of the pilot project. Findings of the impact evaluation give promise that knowledge and practices on integrated malaria prevention can be enhanced if the use of multiple methods are promoted in communities. In addition, CHWs have a key role in promoting integrated malaria prevention particularly in rural communities in endemic countries.

\section{Competing interests}

The authors declare that they have no competing interests.

\section{Acknowledgements}

This work was supported by the World Health Organization Regional Office for Africa (AFRO) Special Programme for Research and Training in Tropical Diseases (TDR) under the AFRO-TDR Small Grants Programme. This investigation also received financial support from TDR, co-sponsored by UNICEF, UNDP, the World Bank and WHO. DM received support from the Africa Research Excellence Fund (AREF) grant number MUSOKEMRF-157-0013-F-MUSOK. We thank the village mobilisers Ssalongo Henry Kajubi and Nnalongo Hadijah, Rornald Muhumuza Kananura as well as the local leaders in the two study areas for their support during the study.

\section{References}

1. WHO. World Malaria Report 2016.Geneva: World Health Organization. 2015 (www.who.int/malaria/publications/world-malaria-report-2016/report/en/)accessed $29^{\text {th }}$ June 2017.

2. Cooke MK, Kahindi SC, Oriango RM, Owaga C, Ayoma E, Mabuka D, et al. 'A bite before bed': exposure to malaria vectors outside the times of net use in the highlands of western Kenya. Malar J. 2015; 14:259.

3. Benelli G, Beier JC. Current vector control challenges

African Health Sciences Vol 18 Issue 4, December, 2018 in the fight against malaria. Acta Trop. 2017; 174: 91-96. 4. Liu JX, Bousema T, Zelman B, Gesase S, Hashim R, Maxwell C, et al. Is housing quality associated with malaria incidence among young children and mosquito vector numbers? Evidence from Korogwe, Tanzania. PLoS One. 2014; 9(2): e87358.

5. Tusting LS, Thwing J, Sinclair D, Fillinger U, Gimnig J, Bonner KE, et al. Mosquito larval source management for controlling malaria. Cochrane Database Syst Rev. 2013; (8):CD008923.

6. Tusting LS, Ippolito MM, Willey BA, Kleinschmidt I, Dorsey G, Gosling RD, et al. The evidence for improving housing to reduce malaria: a systematic review and meta-analysis. Malar J. 2015; 14:209.

7. Bekker LG, Beyrer C, Quinn TC. Behavioral and biomedical combination strategies for HIV prevention. Cold Spring Harbor Perspectives in Medicine. 2012; 2(8)a007435.

8. Uthman OA, Hartley L, Rees K, Taylor F, Ebrahim S, Clarke A. Multiple Risk Factor Interventions for Primary Prevention of Cardiovascular Disease in LMIC: A Cochrane Review. Glob Heart. 2016. pii: S22118160(16)30639-1.

9. Musoke D, Karani G, Ssempebwa JC, Etajak S, Guwatudde D, Musoke MB. Knowledge and practices on malaria prevention in two rural communities in Wakiso District, Uganda. Afr Health Sci. 2015; 15(2): 401-412.

10. Musoke D, Karani G, Ssempebwa JC, Musoke MB. Integrated approach to malaria prevention at household level in rural communities in Uganda: experiences from a pilot project. Malar J. 2013; 12: 327.

11. Foley OW, Birrer N, Rauh-Hain JA, Clark RM, DiTavi E, Del Carmen MG. Effect of Educational Intervention on Cervical Cancer Prevention and Screening in Hispanic Women. J Community Health. 2015. DOI: 10.1007/s10900015-0045-x.

12. Mugisa M, Muzoora A. Behavioral change communication strategy vital in malaria prevention interventions in rural communities: Nakasongola district, Uganda. Pan Afr Med J. 2012; 13 Suppl 1:2.

13. Wu L, He Y, Jiang B, Zuo F, Liu Q, Zhang L, et al. Impact of intervention on tobacco related knowledge, attitudes and practice of smokers. Zhonghua Liu Xing Bing Xue Za Zhi. 2015; 36(2): 119-123.

14. Tobin-West CI, Briggs N. Effectiveness of trained community volunteers in improving knowledge and management of childhood malaria in a rural area of Rivers State, Nigeria. Niger J Clin Pract. 2015; 18(5): 651-658. 
15. Berthe S, Loll D, Faye SL, Wone I, Koenker H, Arnold B, Weber R. "When I sleep under the net, nothing bothers me; I sleep well and I'm happy": Senegal's culture of net use and how inconveniences to net use do not translate to net abandonment. Malar J. 2014; 13: 357. 16. Chukwuocha UM, Dozie IN, Onwuliri CO, Ukaga CN, Nwoke BE, Nwankwo BO, et al. (2010). Perceptions on the use of insecticide treated nets in parts of the Imo River Basin, Nigeria: implications for preventing malaria in pregnancy. Afr J Reprod Health. 2010; 14(1): 117-128.

17. Hlongwana KW, Mabaso ML, Kunene S, Govender D, Maharaj R. Community knowledge, attitudes and practices (KAP) on malaria in Swaziland: a country earmarked for malaria elimination. Malar J. 2009; 8: 29.

18. Legesse Y, Tegegn A, Belachew T, Tushune K. Knowledge, Attitude and Practice about Malaria Transmission and its Preventive Measures among Households in Urban Areas of Assosa Zone, Western Ethiopia. Ethiop. J. Health Dev. 2007; 21(2): 157-165.

19. Bocoum FY, Belemsaga D, Adjagba A, Walker D, Kouanda S, Tinto H. Malaria prevention measures in Burkina Faso: distribution and households expenditures. Int J Equity Health. 2014; 13(1): 108.

20. Salam RA, Das JK, Lassi ZS, Bhutta ZA. Impact of community-based interventions for the prevention and control of malaria on intervention coverage and health outcomes for the prevention and control of malaria. Infect Dis Poverty. 2014; 3: 25.

21. Malaria Consortium. Malaria. A handbook for health professionals. $1^{\text {st }}$ ed. London: Macmillan, 2007.

22. Dickinson KL, Randell HF, Kramer RA, Shayo EH. Socio-economic status and malaria-related outcomes in Mvomero District, Tanzania. Glob Public Health. 2012; 7(4): 384-399.

23. Welch K, Fuster, M. Barriers in access to insecticide-treated bednets for malaria prevention: an analysis of Cambodian DHS data. J Vector Borne Dis. 2012; 49(1):1-7. 24. West PA, Protopopoff N, Rowland M, Cumming E, Rand A, Drakeley C, et al. Malaria risk factors in North West Tanzania: the effect of spraying, nets and wealth. PLoS One. 2013; 8(6): e65787.

25. Anand T, Kumar R, Saini V, Meena G, Ingle G. Knowledge and use of personal protective measures against mosquito borne diseases in a resettlement colony of Delhi. Ann Med Health Sci Res. 2014; 4(2): 227-232.

26. Musoke D, Karani G, Ndejjo R, Okui P, Musoke MB. Experiences of households using integrated malaria prevention in two rural communities in Wakiso district, Uganda: a qualitative study. Malar J. 2016; 15: 313. 